\title{
Combined Treatment With a Nonselective Nitric Oxide Synthase Inhibitor (L-NMMA) and Indomethacin Increases Ductus Constriction in Extremely Premature Newborns
}

\author{
ROBERTA L. KELLER, THERESA A. TACY, SCOTT FIELDS, JOHN P. OFENSTEIN, \\ JACOB V. ARANDA, AND RONALD I. CLYMAN \\ Department of Pediatrics [R.L.K., T.A.T., R.I.C.], Cardiovascular Research Institute [R.L.K., R.I.C.], \\ Pharmacy [S.F.], University of California San Francisco, San Francisco, CA 94143; Clinical \\ Pharmacology/Toxicology [J.P.O., J.V.A.], Children's Hospital of Michigan, Wayne State University, \\ Detroit, MI 48201
}

\begin{tabular}{|c|c|}
\hline \multicolumn{2}{|c|}{ ABSTRACT } \\
\hline $\begin{array}{l}\text { Studies in premature animals suggest that } 1 \text { ) prolonged tight } \\
\text { constriction of the ductus arteriosus is necessary for permanent } \\
\text { anatomic closure and 2) endogenous nitric oxide (NO) and } \\
\text { prostaglandins both play a role in ductus patency. We hypothe- } \\
\text { sized that combination therapy with an NO synthase (NOS) } \\
\text { inhibitor [ } \mathrm{N}^{\mathrm{G}} \text {-monomethyl-L-arginine (L-NMMA)] and indo- } \\
\text { methacin would produce tighter ductus constriction than indo- } \\
\text { methacin alone. Therefore, we conducted a phase I and II study } \\
\text { of combined treatment with indomethacin and L-NMMA in } \\
\text { newborns born at }<28 \text { weeks gestation who had persistent } \\
\text { ductus flow by Doppler after an initial three-dose prophylactic } \\
\text { indomethacin course (0.2, } 0.1,0.1 \mathrm{mg} / \mathrm{kg} / 24 \mathrm{~h}) \text {. Twelve infants } \\
\text { were treated with the combined treatment protocol [three addi- } \\
\text { tional indomethacin doses ( } 0.1 \mathrm{mg} / \mathrm{kg} / 24 \mathrm{~h}) \text { plus a } 72 \text {-hour } \\
\text { L-NMMA infusion]. Thirty-eight newborns received three addi- } \\
\text { tional indomethacin doses (without L-NMMA) and served as a } \\
\text { comparison group. Ninety-two percent }(11 / 12) \text { of the combined } \\
\text { treatment group had tight ductus constriction with elimination of } \\
\text { Doppler flow. In contrast, only } 42 \%(16 / 38) \text { of the comparison }\end{array}$ & $\begin{array}{l}\text { group had a similar degree of constriction. L-NMMA infusions } \\
\text { were limited in dose and duration by acute side effects. Doses of } \\
10-20 \mathrm{mg} / \mathrm{kg} / \mathrm{h} \text { increased serum creatinine and systemic blood } \\
\text { pressure. At } 5 \mathrm{mg} / \mathrm{kg} / \mathrm{h} \text {, serum creatinine was stable but systemic } \\
\text { hypertension still limited L-NMMA dose. We conclude that } \\
\text { combined inhibition of NO and prostaglandin synthesis increased } \\
\text { the degree of ductus constriction in newborns born at }<28 \\
\text { weeks' gestation. However, the combined administration of L- } \\
\text { NMMA and indomethacin was limited by acute side effects in } \\
\text { this treatment protocol. (Pediatr Res 58: 1216-1221, 2005) } \\
\text { GA, gestational age } \\
\text { L-NMMA, NG-monomethyl-L-arginine } \\
\text { NO, nitric oxide } \\
\text { NOS. nitric oxide synthase } \\
\text { PDA, patent ductus arteriosus } \\
\text { PVR, pulmonary vascular resistance } \\
\text { VCFc, rate-corrected velocity of fiber shortening }\end{array}$ \\
\hline
\end{tabular}

Studies in premature animals demonstrate that prolonged, tight constriction of the ductus arteriosus is necessary to produce ischemia of the ductus wall, anatomic remodeling, and

Received January 24, 2005; accepted April 22, 2005.

Correspondence: Roberta L. Keller, M.D., 533 Parnassus Avenue, U585, University of California San Francisco, Box 0748, San Francisco, CA 94143: e-mail: kellerr@ peds.ucsf.edu

Supported by the Pediatric Clinical Research Center, Moffitt Hospital, University of California, San Francisco, with funds provided by the National Center for Research Resources (5 M01 RR-01271), U.S. Public Health Service (NHLBI U01-HL-56061 and HL-46691), and the University of California San Francisco Research and Allocation Committee. Roberta L. Keller is a recipient of the Glaser Pediatric Research Network Award.

DOI: 10.1203/01.pdr.0000183659.20335.12 permanent closure (1-3). A persistent patent ductus arteriosus (PDA) in premature infants is due in large part to the increased sensitivity of the ductus to endogenous vasodilators like prostaglandins. Prostaglandin synthesis inhibitors, such as indomethacin, are the only drugs currently approved for treatment of PDA. Unfortunately, a three-dose course of indomethacin frequently fails to close the PDA in infants of $<28$ weeks gestational age (GA). Previous studies have shown that infants delivered before 28 weeks GA who still have evidence of ductus flow on Doppler examination (performed after a standard three-dose course of indomethacin), are unlikely to eliminate Doppler flow through their ductus even if a prolonged six-dose indomethacin course is administered (2). 
They also have a high likelihood (60-65\% chance) of developing symptoms due to an increased PDA shunt in the future $(2,4)$.

Although NO plays a smaller role than prostaglandins in opposing ductus constriction in vitro (5-7), combined inhibition of both prostaglandin and NO synthesis enabled preterm baboons (approximately 67\% gestation) to maintain tight ductus constriction for 96 hours and to develop anatomic remodeling and permanent ductus closure (1). Therefore, in preterm newborns who have not responded to inhibition of prostaglandin synthesis alone, combined inhibition of both $\mathrm{NO}$ and prostaglandin synthesis may be required to produce the degree of constriction that results in ductus ischemia and remodeling $(1,7)$.

To examine the role of $\mathrm{NO}$ in persistent PDA in human infants, we conducted a phase I/II clinical trial of combined treatment with indomethacin and the competitive NOS inhibitor L-NMMA $(1,8)$ in newborns delivered before 28 weeks GA who still had Doppler evidence of persistent ductus flow after three doses of indomethacin. Our study aims were 1) to determine the appropriate and safe dosing of L-NMMA that would enable us to administer a 72-hour L-NMMA infusion combined with indomethacin treatment, and 2) to establish that combined treatment (with indomethacin and L-NMMA) would produce a tighter degree of ductus constriction than indomethacin alone. We hypothesized that if a tight degree of ductus constriction could be maintained for 72 hours, ductus remodeling and permanent closure might occur.

\section{METHODS}

This study was conducted in the University of California San Francisco (UCSF) Intensive Care Nursery under the approval of the UCSF Committee on Human Research. L-NMMA was available for use under an investigatorsponsored Investigational New Drug (IND) exemption from the U.S. Food and Drug Administration. Written, informed consent was obtained from parents of all subjects. A Data Safety Monitoring Committee reviewed safety data annually and approved continued enrollment through the study period.

Standard nursery protocol. During the period of this study (January 1, 1999-September 1, 2003), all newborns of $\leq 27$ 6/7 weeks' GA admitted to our nursery received prophylactic indomethacin beginning 10-15 hours after delivery (a three-dose regimen: initial dose of $0.2 \mathrm{mg} / \mathrm{kg}$, followed by 0.1 $\mathrm{mg} / \mathrm{kg} / 24 \mathrm{~h}$ for doses 2 and 3). Between 10 and 20 hours after the third dose of indomethacin, echocardiography was performed. If any ductus flow was seen on the Doppler exam, a fourth, fifth, and sixth dose of $0.1 \mathrm{mg} / \mathrm{kg}$ indomethacin was given every 24 hours (prolonged indomethacin-alone protocol) (2). A second echocardiogram was obtained 24 hours after the last dose of indomethacin to see whether the ductus had undergone additional constriction. Following the second echocardiogram, infants were monitored daily for the development of a clinically significant PDA. A clinically significant PDA was defined as the presence of the following three symptoms: 1) a prolonged systolic murmur, 2) the presence of bounding pulses, and 3) a hyperactive precordium. If symptoms of a clinically significant PDA developed, a third echocardiogram was obtained. If this study documented the presence of both increased ductus diameter and increased luminal blood flow, the ductus was considered to have reopened, and the infant was treated with a second course of indomethacin or surgically ligated. The decision to treat with indomethacin or surgical ligation was made by the attending neonatologist and was based on the severity of the clinical symptoms and whether there were any contraindications to the use of indomethacin. Patients were not enterally fed while receiving indomethacin in accord with our nursery policy.

Subject inclusion/exclusion criteria. Newborns with persistent ductus flow by Doppler after the three initial indomethacin doses were eligible for the study. The need for mechanical ventilation was not a criterion for study eligibility. Newborns were excluded if there were contraindications to further indomethacin administration (serum creatinine $>2.0 \mathrm{mg} / \mathrm{dL}$, necrotizing enterocolitis, active hemorrhage with abnormal clotting time, and culture-proven bacteremia without adequate antibiotic therapy for at least 24 hours). Newborns were also excluded if there were contraindications to L-NMMA administration: systemic hypertension (mean arterial pressure $>50 \mathrm{~mm} \mathrm{Hg}$ ), evidence of suprasystemic pulmonary hypertension, $\mathrm{FiO}_{2}>0.60$, or grade III/ IV intracranial hemorrhage.

Combined treatment protocol. The combined treatment protocol $(\mathrm{L}-$ NMMA and indomethacin) consisted of the standard additional fourth, fifth, and sixth dose of $0.1 \mathrm{mg} / \mathrm{kg}$ indomethacin (starting 24 hours after the third dose) plus a continuous infusion of L-NMMA (Clinalfa, Laufelfingen, Switzerland; $250 \mathrm{mg}$ ampules mixed in D10W to a final concentration of 10-20 $\mathrm{mg} / \mathrm{kg} / \mathrm{mL}$ by the UCSF investigational drug pharmacy). The planned duration of the L-NMMA infusion was 72 hours, to be administered during the fourth, fifth and sixth doses of L-NMMA.

L-NMMA infusion was always begun at a dose of $5 \mathrm{mg} / \mathrm{kg} / \mathrm{h}$ for 2 hours, and the dose was increased as tolerated to reach the targeted dose. The initial targeted dose of the L-NMMA infusion was $20 \mathrm{mg} / \mathrm{kg} / \mathrm{h}$ (based on studies performed in preterm baboons of comparable gestation) (1). However, acute side effects limited the L-NMMA dose and the targeted infusion dose was progressively lowered to $5 \mathrm{mg} / \mathrm{kg} / \mathrm{h}$ (Table 1). Individual subject dose increases were aborted and the L-NMMA dose was lowered if persistent systemic hypertension developed (mean arterial pressure $>50 \mathrm{~mm} \mathrm{Hg}$ ). In subjects who were receiving dopamine to support systemic blood pressure before the L-NMMA infusion, the dopamine was weaned as tolerated. L-NMMA was discontinued if a contraindication to either indomethacin or L-NMMA developed or if there was a significant, unexplained clinical decline during the treatment protocol. Indomethacin was also discontinued if a contraindication to its administration developed (see above).

Study monitoring and L-NMMA measurements. Subjects were monitored with an indwelling arterial line, pulse oximeter, and cardiorespiratory monitor during the combined indomethacin/L-NMMA treatment. Measurements of serum chemistries (including blood urea nitrogen, total and direct bilirubin, aspartate aminotransferase, alanine aminotransferase, and creatine kinase) and

Table 1. Acute effects of combined treatment with $L-N M M A$ and indomethacin in study subjects

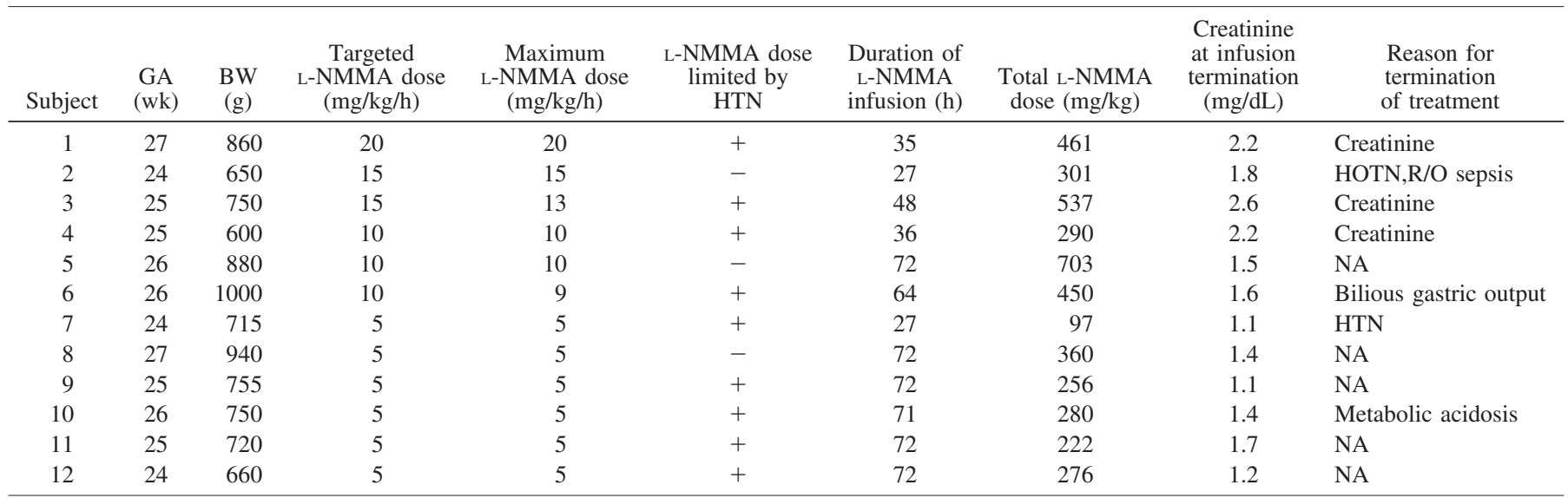

BW, birth weight; HTN, systemic hypertension; HOTN, systemic hypotension; R/O, rule out; NA, not applicable. 
electrolytes, complete blood count with platelets, arterial blood gases, and ECG were obtained before and after completion of the L-NMMA infusion. Additional measurements of arterial blood gases (at least four times per day) and serum creatinine (daily) were made while patients received the combined treatment.

Pulmonary function tests were performed on intubated newborns $(n=11)$ using an in-line pneumotachometer $\left(\mathrm{CO}_{2} \mathrm{SMO}\right.$ Plus respiratory monitor, Novametrix Medical Systems, Wallingford, CT) before and 6-24 hours after starting the L-NMMA infusion to evaluate the acute effects of NOS inhibition. Between eight and 20 uniform, representative breaths from each time point were selected for subsequent analysis

Echocardiographic indices of cardiac performance and vascular resistance were obtained before and 6-24 hours after starting the L-NMMA infusion ( $n$ =9) using standard imaging transducers (Sequoia ultrasound system, Siemens Medical Solutions, Mountain View, CA). Flow within the middle cerebral artery and the superior mesenteric artery were sampled by pulsed wave Doppler [using a sagittal fontanellar approach $(9,10)$ and a transabdomina sagittal approach (11), respectively]; resistive indices (RI) were calculated from the waveforms. Cardiac output was estimated by Doppler echocardiography (12). The shortening fraction, ejection time, rate-corrected velocity of fiber shortening $(\mathrm{VCF})$, and left ventricular peak meridional wall stress were performed according to standard methods $(13,14)$.

Plasma L-NMMA measurements $(0.1 \mathrm{~mL}$ plasma $)$ were obtained 24 hours after starting L-NMMA, and following discontinuation ( $0,1,3,6,12$ hours), The plasma samples were supplemented with 8.0 pmol of L-NMMA and derivatized with Waters AccQ92Fluor Reagent. The derivatives were separated by reversed-phase high-performance liquid chromatography (HPLC) and quantitated by fluorescence detection. The HPLC column $(100 \times 4.6 \mathrm{~mm} \mathrm{I.D.})$ was packed with 5-pm particles of Spherisorb ODS2 (Technicol, Stockport, U.K.). No guard column was used and the analytical column ran at ambient temperature. The detector was set at $240-\mathrm{nm}$ wavelength excitation with a 418-nm cutoff filter for emission. A stepwise gradient elution mobile phase was used to optimize the chromatography conditions. The gradient mobile phase consisted of solvent $\mathrm{A}$ [acetonitrile $(\mathrm{pH}$ 5.8)-water-dimethylsulfoxide $(10: 71: 10 . \mathrm{vol} / \mathrm{vol})]$ and solvent B [acetonitrile-water-dimethylsulfoxide $(50: 40: 10 . \mathrm{vol} / \mathrm{vol})]$. The gradient conditions were at time $0 \mathrm{~min}, 2.5 \% \mathrm{~B}$; at 10 $\mathrm{min}, 0 \% \mathrm{~B}$; at $10.1 \mathrm{~min}, 100 \% \mathrm{~B}$; at $11.0 \mathrm{~min}, 100 \% \mathrm{~B}$; at $11.1 \mathrm{~min}, 0 \% \mathrm{~B}$; at $16 \mathrm{~min}$ loop to time 0 run; the flow rate was $1.5 \mathrm{~mL} / \mathrm{min}$. Calibration standards $(0.10-50.0 \mathrm{pmol} / \mathrm{L})$ were situated at the beginning and end of each analytical run. The regression line of the peak areas of the calibration standard concentrations was used to calculate test analyte concentrations (coefficient of variance was $<2.5 \%$ )

Study and comparison groups. Two hundred three newborns of less than 28 weeks GA received prophylactic indomethacin between January 1999 and September 2003. Fifty infants had persistence of ductus flow by Doppler after three indomethacin doses and received a prolonged indomethacin course. Twelve newborns were enrolled in the combined treatment protocol. The 38 newborns who did not receive L-NMMA [because the drug was not available or the parents declined to participate $(n=7)]$ served as a contemporary comparison group for the study infants. Antenatal, demographic, and neonatal data were collected prospectively.

Demographic and perinatal characteristics in infants treated with the combined treatment protocol and those in the contemporary comparison group (prolonged indomethacin alone) were similar, including GA $[25.3 \pm 1.1$ versus $25.6 \pm 1.2$ weeks, for the combined treatment and comparison groups ( $\mathrm{L}-$ NMMA and indomethacin and indomethacin-alone, respectively)], birth weight (774 \pm 123 versus $853 \pm 215 \mathrm{~g}$ ), male sex (50\% versus $61 \%)$, antenatal steroid exposure $>6$ hours before delivery ( $58 \%$ versus $71 \%$ ), respiratory distress syndrome ( $92 \%$ versus $87 \%$ ), and fluid intake during the first $4 \mathrm{~d}$ of life (data not shown). Later neonatal morbidities also occurred at similar rates in the two treatment groups: chronic lung disease incidence was $45 \%$ versus $60 \%$ for combined treatment and indomethacin-alone groups, respectively; necrotizing enterocolitis, $17 \%$ versus $30 \%$; bacteremia, $58 \%$ versus $66 \%$; intracranial hemorrhage (grades III/IV) and/or cystic periventricular leukomalacia, $8 \%$ versus $18 \%$; retinopathy of prematurity, $73 \%$ versus $43 \%$; and surgery for retinopathy of prematurity, $18 \%$ versus $13 \%$. Survival to hospital discharge was similar as well (92\% versus $76 \%$ ).

Statistical analysis. Data were analyzed by $\chi^{2}$, Fisher's exact test, $t$ test, Mann-Whitney rank sum test, Wilcoxon sign-rank test, repeated-measures analysis of variance, and Cox proportional hazards, as appropriate. Statistical analyses (Stata 6.0, Stata Corp., College Station, TX) were two tailed. A $p$ value of $<0.05$ was considered significant. Data are presented as mean \pm SD unless otherwise indicated.

\section{RESULTS}

Acute effects of combined treatment with indomethacin and $L-N M M A$. The $L-N M M A$ infusion was begun at $5 \mathrm{mg} / \mathrm{kg} / \mathrm{h}$ for 2 hours. This dose caused a significant increase in systemic blood pressure (Fig. 1). There was no significant effect on heart rate.

Our initial targeted L-NMMA infusion dose was $20 \mathrm{mg} / \mathrm{kg} / \mathrm{h}$. However, we were unable to maintain this infusion dose due to elevated serum creatinine and systemic hypertension. Targeted L-NMMA infusion doses of $10-20 \mathrm{mg} / \mathrm{kg} / \mathrm{h}$ were associated with a significant increase in serum creatinine, which resulted in premature termination of the combined treatment in three subjects (Fig. 2, Table 1). The targeted L-NMMA dose was progressively decreased until a dose was reached that did not appear to significantly impair creatinine clearance $(5 \mathrm{mg} / \mathrm{kg} / \mathrm{h}$, Fig. 2). No subject required early termination of combined treatment due to elevated serum creatinine when the targeted L-NMMA dose was $5 \mathrm{mg} / \mathrm{kg} / \mathrm{h}$ (Table 1). Urine output was $>1.5 \mathrm{~mL} / \mathrm{kg} / \mathrm{h}$ in all subjects and creatinine normalized in all cases when combined treatment was discontinued (data not shown).

Systemic hypertension limited L-NMMA infusion doses in the majority of subjects at all dosing levels (Table 1). Even at the targeted dose of $5 \mathrm{mg} / \mathrm{kg} / \mathrm{h}$, the infusion rate had to be decreased during the treatment period in $83 \%(5 / 6)$ of the subjects due to mean blood pressure $>50 \mathrm{~mm} \mathrm{Hg}$. Systemic hypertension resolved when the L-NMMA infusion rate was decreased in all but one subject. In this subject, systemic blood pressure was increasing before the L-NMMA infusion, continued to increase during the infusion, and did not decrease when the L-NMMA infusion was discontinued. Ultimately, this infant required systemic vasodilator therapy for several days.

The L-NMMA plasma concentrations at the end of the infusion were $123 \pm 122 \mu \mathrm{g} / \mathrm{mL}$ for infusion rates $\geq 10$ $\mathrm{mg} / \mathrm{kg} / \mathrm{h}(10.3 \pm 0.8 \mathrm{mg} / \mathrm{kg} / \mathrm{h})$ and $23 \pm 18 \mu \mathrm{g} / \mathrm{mL}$ for infusion rates $<10 \mathrm{mg} / \mathrm{kg} / \mathrm{h}(4.3 \pm 3.0 \mathrm{mg} / \mathrm{kg} / \mathrm{h})$. Plasma concentrations declined to $45 \pm 20 \%$ of the prediscontinuation levels 1 hour

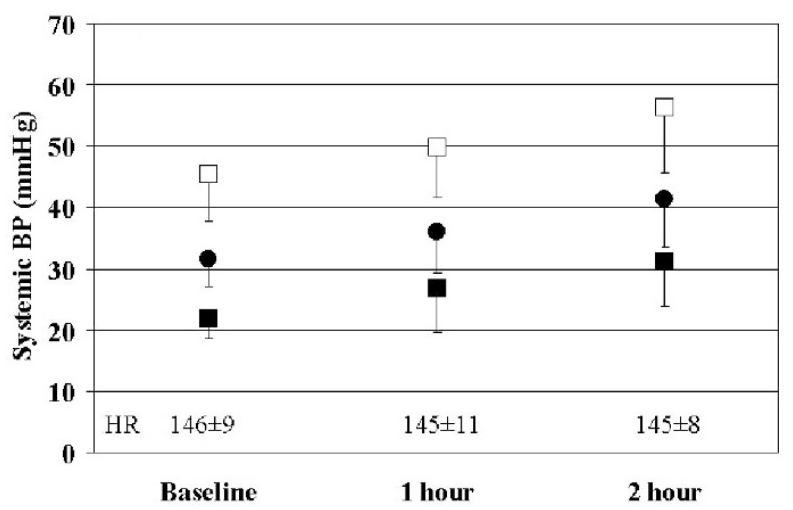

Figure 1. Systemic blood pressure (BP) and heart rate before and during the first 2 hours of combined treatment (L-NMMA infusion $5 \mathrm{mg} / \mathrm{kg} / \mathrm{h})(n=12)$. SBP $(\square)$ indicates systolic blood pressure; DBP $(\mathbf{\square})$, diastolic blood pressure; MAP (๑), mean arterial pressure; HR, heart rate. Changes in HR were not significant. SBP, DBP, and MAP increased significantly during the 2-hour interval $(p<0.0005$ for all comparisons, by repeated-measures analysis of variance). 
A

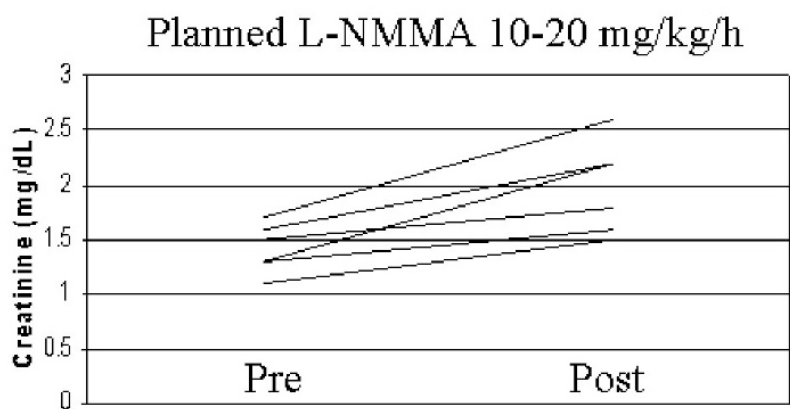

B

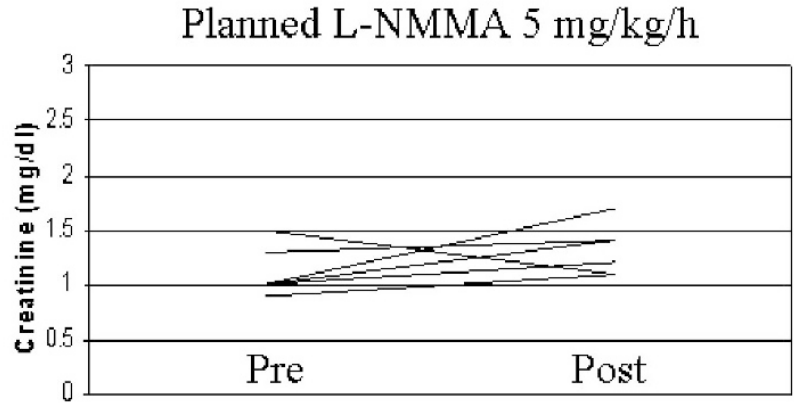

Figure 2. Serum creatinine before and after combined treatment with LNMMA and indomethacin. (A) Subjects with planned L-NMMA infusion of $10-20 \mathrm{mg} / \mathrm{kg} / \mathrm{h}(n=6)$ had a significant increase in serum creatinine $(p=$ 0.004). (B) Subjects with planned L-NMMA infusion of $5 \mathrm{mg} / \mathrm{kg} / \mathrm{h}(n=6) \mathrm{had}$ no significant change in serum creatinine $(p=0.24)$.

after discontinuing the infusion, $10 \pm 16 \%$ after 3 hours, and $0 \pm 10 \%$ after 6 hours.

The combined treatment protocol was not associated with a significant change in the infants' dynamic respiratory system compliance, peak expiratory flow, Fio ${ }_{2}$ requirement, or mean airway pressure (Table 2). The combined treatment protocol did not appear to affect the normal relationship between cardiac contractility and afterload (VCFc versus wall stress, Fig. 3) or any of the other indices of cardiac performance (ejection fraction, shortening fraction, and cardiac output, Table 2).

Table 2. Measures of lung and cardiac function and systemic vascular resistance before and during combined treatment with L-NMMA and indomethacin

\begin{tabular}{lccl}
\hline & Pretreatment & During treatment* & $p$ \\
\hline $\mathrm{Crs}\left(\mathrm{mL} / \mathrm{cm} \mathrm{H} \mathrm{H}_{2} \mathrm{O} / \mathrm{kg}\right)$ & $0.65 \pm 0.41$ & $0.65 \pm 0.42$ & 0.82 \\
$\mathrm{PEF}(\mathrm{L} / \mathrm{min})$ & $2.0 \pm 0.6$ & $2.1 \pm 0.6$ & 0.79 \\
$\mathrm{Paw}\left(\mathrm{cm} \mathrm{H} \mathrm{H}_{2} \mathrm{O}\right)$ & $6.8 \pm 1.2$ & $6.2 \pm 0.8$ & 0.06 \\
$\mathrm{Fio}_{2}$ & $0.23 \pm 0.03$ & $0.22 \pm 0.02$ & 0.50 \\
$\mathrm{Ventilator} \mathrm{index} \dagger_{\text {Ejection fraction }}^{151 \pm 28}$ & $137 \pm 19$ & 0.13 \\
Shortening fraction & $63.7 \pm 10.5 \%$ & $60.2 \pm 10.3 \%$ & 0.37 \\
Cardiac output $\left(\mathrm{L} / \mathrm{min} / \mathrm{m}^{2}\right)$ & $1.66 \pm 0.48$ & $38.5 \pm 4.4 \%$ & 0.86 \\
SMA RI & $0.81 \pm 0.08$ & $0.82 \pm 0.86$ & 0.67 \\
MCA RI & $0.77 \pm 0.08$ & $0.70 \pm 0.10$ & 0.76 \\
\hline
\end{tabular}

* Paw and $\mathrm{FiO}_{2}$ collected at 24 hours of combined treatment $(n=12)$. Lung function $(n=11)$ and hemodynamic $(n=9)$ measures obtained 6-24 hours after start of combined treatment.

$\dagger$ Ventilator index $=\mathrm{Paw} \times \mathrm{Fio}_{2} \times 100$

Crs, respiratory system compliance; PEF, peak expiratory flow; Paw, mean airway pressure; $\mathrm{FiO}_{2}$, inspired oxygen concentration; $\mathrm{EF}$, ejection fraction; $\mathrm{SF}$, shortening fraction; CO, cardiac output; SMA, superior mesenteric artery; MCA, middle cerebral artery; RI, resistive index.

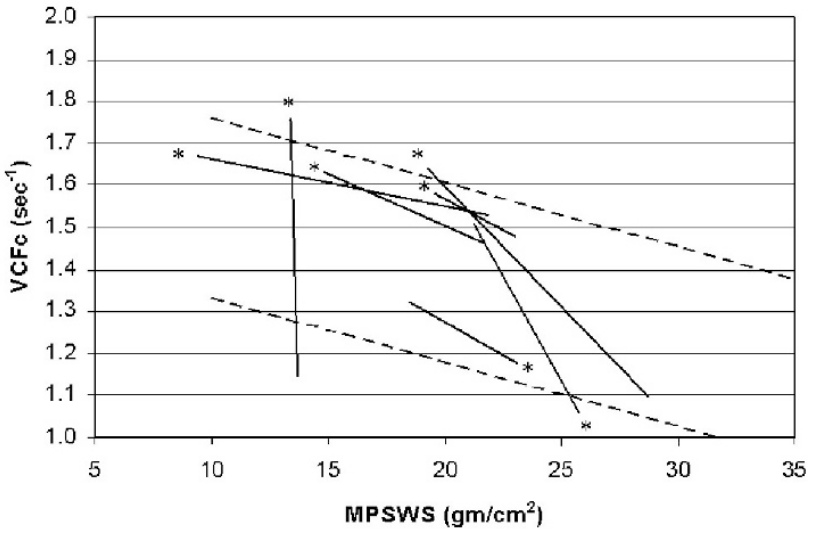

Figure 3. Relationship of $\mathrm{VCFc}$ and meridional peak systolic wall stress (MPSWS) in infants with combined treatment with indomethacin and LNMMA $(n=7)$. Measures for individual subjects are plotted before and during treatment (6-24 hours after start of combined treatment). Pretreatment points are marked with asterisk. Dashed lines represent normal range for healthy preterm infants without PDA (14).

There was no change in the superior mesenteric artery resistive index during the combined treatment protocol, but there was a trend toward a decrease in the vascular resistance in the middle cerebral artery (decrease in the resistive index, Table 2).

There were no other concerning electrocardiographic, metabolic, or hematologic changes following the conclusion of the combined treatment protocol (see Methods, data not shown).

Effects of combined treatment on the ductus arteriosus. We have previously shown that infants with an open ductus after the standard three-dose course of indomethacin have only a $47 \%$ chance of closing their ductus when the course is extended to a total of six indomethacin doses (prolonged indomethacin-alone protocol) (2). Similarly, only $42 \%$ of our contemporary comparison group of 38 infants (indomethacinalone group) developed tight ductus constriction (no evidence of ductus flow by Doppler) at the conclusion of their treatment (5.8 \pm 0.8 indomethacin doses). The rate of tight ductus constriction following the combined treatment protocol with L-NMMA and indomethacin group (92\%), however, was significantly higher than that of the contemporary comparison group (92\% versus $42 \%, p=0.003$ ). Tight ductus constriction occurred early in the combined treatment group; 10/12 had no ductus flow (by Doppler) within 24 hours of starting the L-NMMA infusion.

Despite the high incidence of tight ductus constriction in the combined treatment group, most of these infants ultimately reopened their ductus and were surgically ligated $(7 / 12,58 \%)$. The duration of L-NMMA infusion was related to the rate of ductus reopening; the longer infants were infused with LNMMA, the lower the risk of ductus reopening. Each additional 12-hour interval of L-NMMA infusion was associated with a $40 \%$ reduction in the risk of reopening (hazard ratio $0.60 ; 95 \%$ confidence interval $0.37-0.97 ; p=0.04$ ).

\section{DISCUSSION}

Human preterm infants who have no clinical evidence of a PDA but who still have Doppler evidence of ductus flow following three doses of indomethacin are likely to develop 
significant PDA-related symptoms in the future $(2,4)$. Previous studies in preterm animals have suggested that both the degree and the duration of ductus constriction determine the likelihood of permanent ductus closure after birth $(1,3)$. In the current study, we were able to achieve a higher rate of tight ductus constriction (elimination of Doppler ductus flow) with combined L-NMMA and indomethacin treatment compared with treatment with indomethacin-alone ( $92 \%$ versus $42 \%$ ).

Despite the high rate of tight ductus constriction, we still had an unacceptably high rate of clinical ductus reopening (58\%) after combined treatment. We hypothesized that maintenance of tight ductus constriction, through inhibition of both prostaglandin and NO synthesis, would produce ductus remodeling and permanent closure in these extremely premature newborns. Unfortunately, in this phase I/II trial, we achieved our planned L-NMMA infusion of 72 hours in only half (5/12) of the infants (due to side effects of the L-NMMA or other significant changes in the infants' condition). These clinical changes resulted in both a shorter duration of L-NMMA infusion and fewer doses of indomethacin. Although our study is limited by the small number of subjects who received the prolonged duration of combined treatment, infants who received the L-NMMA infusion for $>60$ hours had a significantly higher incidence of permanent ductus closure than those receiving a shorter duration of combined treatment (all $\leq 48$ hours, Table $3)$. This is consistent with the finding that longer L-NMMA infusions corresponded to decreased and delayed ductus reopening (hazard ratio 0.60 for every 12 hours of L-NMMA infusion). However, there was no difference in the total dose of L-NMMA. These data suggest that it is the total duration of combined therapy that is important in achieving permanent ductus closure. All infants with permanent ductus closure had both 1) tight ductus constriction (by Doppler) within 24 hours of starting the treatment and 2) at least 40 additional hours of combined treatment after tight constriction was documented. These findings are consistent with our experience in premature animals and humans $(1-5,7)$. They suggest that endogenous NO plays a role in persistent patency of the preterm PDA and that prolonged maintenance of tight ductus constriction (by inhibition of prostaglandin synthesis alone or in combination with NO synthesis inhibition) can produce permanent ductus closure in extremely premature newborns.

This study also provides the first information about the role of endogenous NO in other vascular beds in human premature newborns. Inhibition of NO production produces increases in systemic blood pressure and vascular resistance in healthy adult volunteers $(15,16)$. Its effects are more pronounced in adults with septic shock, in which systemic NO production is increased (17-19). All the preterm infants responded to the L-NMMA infusion with a marked increase in systemic blood pressure while maintaining a normal cardiac contractility/wall stress relationship. This suggests that endogenous NO plays a significant role in the hypotensive "warm shock" that frequently occurs in these infants during the first week after birth (20). In fact, the marked sensitivity of the systemic blood pressure to NO inhibition was a limiting factor in the amount of L-NMMA that could be administered to most of the infants in the study (Table 1).

In term experimental animals, endogenous NO production is critical for the normal perinatal decrease in PVR required to transition from fetal to neonatal circulation $(21,22)$. NO is also important for maintenance of normal pulmonary vascular tone, and NOS inhibition increases PVR in healthy and septic adults (15-19). Despite these observations, at the L-NMMA doses used in this study, we did not see any evidence of abnormal PVR by clinical or echocardiographic parameters in our preterm subjects. Endogenous NO also has been implicated in attenuation of bronchoconstriction in response to noxious stimuli and exogenous NO can serve as a bronchodilator in these situations (23-25). We were unable to demonstrate any significant effect of L-NMMA on pulmonary function through paired measures of respiratory system compliance, expiratory flow, or ventilator requirements. This lack of impact on lung function during the L-NMMA infusion is consistent with observations made in preterm baboons treated with the same protocol (1).

Inhibition of endogenous NO production has a small effect on renal function in unanesthetized healthy adults $(26,27)$. However, during stress, both endogenous NO and prostaglandins appear to play a significant role in maintaining adult renal function (28). Combined NO and prostaglandin synthesis inhibition caused significant elevations in serum creatinine in study infants despite maintenance of normal urine output volume (Fig. 2). This resulted in a high rate of early termination of the combined treatment at L-NMMA infusion rates greater than $5 \mathrm{mg} / \mathrm{kg} / \mathrm{h}$ (Table 1).

Although NOS inhibition increases the resistance in the superior mesenteric and hepatic vascular beds in adult animals $(29,30)$, we observed no effect of L-NMMA on either the

Table 3. Comparison of infants in the combined treatment protocol by duration of L-NMMA infusion

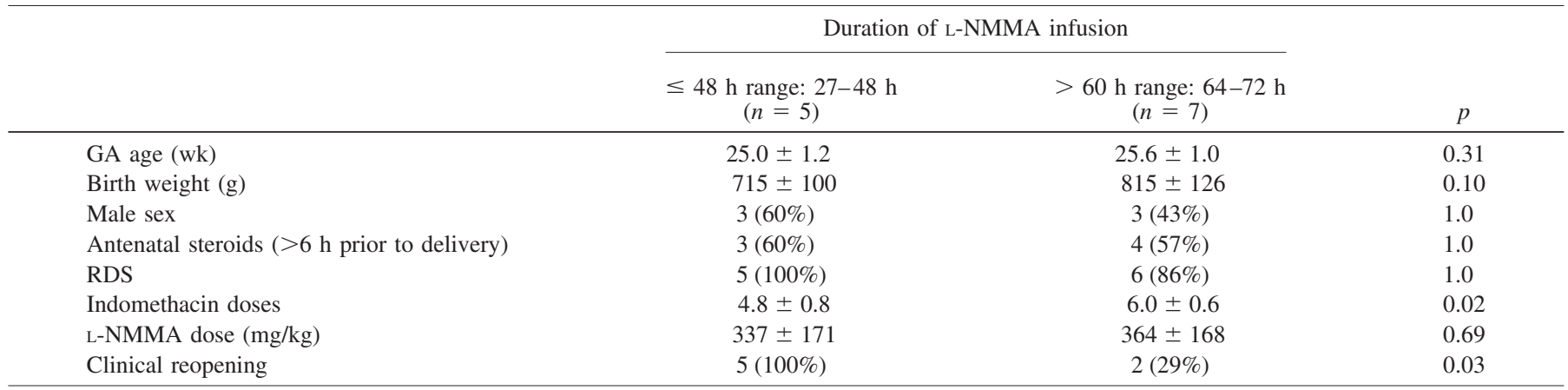

RDS, respiratory distress syndrome. 
superior mesenteric artery resistive index or on indices of hepatocellular injury.

L-NMMA is cleared predominantly by hepatic amino acid pathways, with a minor amount of renal clearance at higher doses (31). In healthy adults, the mean elimination half-life of a $3 \mathrm{mg} / \mathrm{kg}$ L-NMMA dose is about 1 hour (26,32). In contrast, septic adults have a longer elimination half-life (2-3 hours) (31). Based on the limited number of data points in the current study, the elimination half-life of L-NMMA in extremely preterm infants appears to be similar to that reported in healthy adults (with plasma levels falling to $45 \%$ of prediscontinuation values at 1 hour and $10 \%$ at 3 hours).

In conclusion, we have demonstrated increased ductus constriction in extremely preterm newborns ( $<28$ weeks GA) when NOS inhibition is added to indomethacin for treatment of PDA. This supports the role of NO in the maintenance of the patency of the preterm PDA $(1,3,5,7)$. Our data also suggest that prolonged ductus constriction may be required to achieve ductus wall ischemia and permanent ductus closure in premature newborns. However, the combination of NOS and cyclooxygenase inhibitors used in the current study resulted in reversible impaired glomerular filtration and systemic hypertension. The full safety profile of this treatment is still lacking, with our study limited by its small numbers. Further, this phase I/II trial was not a randomized study so our evaluation of treatment efficacy is limited to comparisons with a contemporary control group and our historical data (both groups received prolonged indomethacin alone) (2). Therefore, we believe that before designing a randomized, controlled trial to test the efficacy of combined treatment with $\mathrm{NO}$ and prostaglandin synthesis inhibitors for treatment of PDA, additional safety and feasibility studies in preterm newborns should be conducted.

Acknowledgments. We thank the fellows and attending staff of the Division of Pediatric Cardiology, who have been so helpful in performing and interpreting the echocardiographic studies, and the ICN and PCRC nurses, without whom this study would not have been possible. We also thank Drs. Julien Hoffman, James Bristow, and Jeffrey Fineman for their expert help with data and safety management.

\section{REFERENCES}

1. Seidner SR, Chen YQ, Oprysko PR, Mauray F, Tse MM, Lin E, Koch C, Clyman RI 2001 Combined prostaglandin and nitric oxide inhibition produces anatomic remodeling and closure of the ductus arteriosus in the premature newborn baboon. Pediatr Res 50:365-373

2. Quinn D, Cooper B, Clyman RI 2002 Factors associated with permanent closure of the ductus arteriosus: a role for prolonged indomethacin therapy. Pediatrics 110:e10

3. Kajino H, Chen YQ, Seidner SR, Waleh N, Mauray F, Roman C, Chemtob S, Koch C, Clyman RI 2001 Factors that increase the contractile tone of the ductus arteriosus also regulate its anatomic remodeling. Am J Physiol Regulatory Integrative Comp Physiol 281:R291-R301

4. Narayanan M, Cooper B, Weiss H, Clyman RI 2000 Prophylactic indomethacin: factors determining permanent ductus arteriosus closure. J Pediatr 136:330-337

5. Clyman RI, Waleh N, Black SM, Riemer RK, Mauray F, Chen YQ 1998 Regulation of ductus arteriosus patency by nitric oxide in fetal lambs: the role of gestation, oxygen tension, and vasa vasorum. Pediatr Res 43:633-644

6. Coceani F, Kelsey L, Seidlitz E 1994 Occurrence of endothelium-derived relaxing factor-nitric oxide in the lamb ductus arteriosus. Can J Physiol Pharmacol 72:82-88
7. Momma K, Toyono M 1999 The role of nitric oxide in dilating the fetal ductus arteriosus in rats. Pediatr Res 46:311-315

8. Southan GJ, Szabo C 1996 Selective pharmacological inhibition of distinct nitric oxide synthase isoforms. Biochem Pharmacol. 51:383-394

9. Mitchell DG, Merton D, Needleman L, Kurtz AB, Goldberg BB, Levy D, Rifkin MD, Pennell RG, Vilaro M, Baltarowich O, et al 1988 Neonatal brain: color Doppler imaging. Part I. Technique and vascular anatomy. Radiology 167:303-306

10. Bahlmann F, Reinhard I, Krummenauer F, Neubert S, Macchiella D, Wellek S 2002 Blood flow velocity waveforms of the fetal middle cerebral artery in a normal population: reference values from 18 weeks to 42 weeks of gestation. J Perinat Med 30:490-501

11. Martinussen M, Brubakk AM, Vik T, Yao AC 1997 Relationship between intrauterine growth retardation and early postnatal superior mesenteric artery blood flow velocity. Biol Neonate 71:22-30

12. Lewis JF, Kuo LC, Nelson JG, Limacher MC, Quinones MA 1984 Pulsed Doppler echocardiographic determination of stroke volume and cardiac output: clinical validation of two new methods using the apical window. Circulation 70:425-431

13. Colan SD, Borow KM, Neumann A 1984 Left ventricular end-systolic wall stressvelocity of fiber shortening relation: a load-independent index of myocardial contractility. J Am Coll Cardiol 4:715-724

14. Barlow AJ, Ward C, Webber SA, Sinclair BG, Potts JE, Sandor GG 2004 Myocardial contractility in premature neonates with and without patent ductus arteriosus. Pediatr Cardiol 25:102-107

15. Stamler JS, Loh E, Roddy MA, Currie KE, Creager MA 1994 Nitric oxide regulates basal systemic and pulmonary vascular resistance in healthy humans. Circulation 89:2035-2040

16. Albert J, Schedin U, Lindqvist M, Melcher A, Hjemdahl P, Frostell C 1997 Blockade of endogenous nitric oxide production results in moderate hypertension, reducing sympathetic activity and shortening bleeding time in healthy volunteers. Acta Anaesthesiol Scand 41:1104-1113

17. Petros A, Lamb G, Leone A, Moncada S, Bennett D, Vallance P 1994 Effects of a nitric oxide synthase inhibitor in humans with septic shock. Cardiovasc Res 28:34-39

18. Avontuur JA, Tutein Nolthenius RP, van Bodegom JW, Bruining HA 1998 Prolonged inhibition of nitric oxide synthesis in severe septic shock: a clinical study. Crit Care Med 26:660-667

19. Watson D, Grover R, Anzueto A, Lorente J, Smithies M, Bellomo R, Guntupalli K, Grossman S, Donaldson J, Donaldson J, Le Gall JR, Glaxo Wellcome International Septic Shock Study Group 2004 Cardiovascular effects of the nitric oxide synthase inhibitor NG-methyl-L-arginine hydrochloride (546C88) in patients with septic shock: results of a randomized, double-blind, placebo-controlled multicenter study (study no. 144-002). Crit Care Med 32:13-20.

20. Osborn DA, Evans N, Kluckow M 2004 Clinical detection of low upper body blood flow in very premature infants using blood pressure, capillary refill time, and central-peripheral temperature difference. Arch Dis Child Fetal Neonatal Ed 89:F168_ F173

21. Moore P, Velvis H, Fineman JR, Soifer SJ, Heymann MA 1992 EDRF inhibition attenuates the increase in pulmonary blood flow due to oxygen ventilation in fetal lambs. J Appl Physiol 73:2151-2157

22. Fineman JR, Wong J, Morin FC 3rd, Wild LM, Soifer SJ 1994 Chronic nitric oxide inhibition in utero produces persistent pulmonary hypertension in newborn lambs. J Clin Invest 93:2675-2683

23. Dupuy PM, Shore SA, Drazen JM, Frostell C, Hill WA, Zapol WM 1992 Bronchodilator action of inhaled nitric oxide in guinea pigs. J Clin Invest 90:421-428

24. Nijkamp FP, van der Linde HJ, Folkerts G 1993 Nitric oxide synthesis inhibitors induce airway hyperresponsiveness in the guinea pig in vivo and in vitro. Role of the epithelium. Am Rev Respir Dis 148:727-734

25. Schuiling M, Zuidhof AB, Bonouvrie MA, Venema N, Zaagsma J, Meurs H 1998 Role of nitric oxide in the development and partial reversal of allergen-induced airway hyperreactivity in conscious, unrestrained guinea-pigs. $\mathrm{Br} \mathrm{J}$ Pharmacol 123:1450-1456

26. Haynes WG, Hand MF, Dockrell ME, Eadington DW, Lee MR, Hussein Z, Benjamin N, Webb DJ 1997 Physiological role of nitric oxide in regulation of renal function in humans. Am J Physiol 272:F364-F371

27. Perinotto P, Biggi A, Carra N, Orrico A, Valmadre G, Dall'Aglio P, Novarini A, Montanari A 2001 Angiotensin II and prostaglandin interactions on systemic and renal effects of L-NAME in humans. J Am Soc Nephrol 12:1706-1712

28. Kramer HJ, Horacek V, Backer A, Vaneckova I, Heller J 2004 Relative roles of nitric oxide, prostanoids and angiotensin II in the regulation of canine glomerular hemodynamics. A micropuncture study. Kidney Blood Press Res 27:10-17

29. Bauer C, Walcher F, Kalweit U, Larsen R, Marzi I 1997 Role of nitric oxide in the regulation of the hepatic microcirculation in vivo. J Hepatol 27:1089-1095

30. Yuksel BC, Tanriverdi P, Ozel H, Avsar FM, Topaloglu S, Iskit AB 2003 The effects of nitric oxide synthase blockers on mesenteric blood flow with bile duct ligation. Hepatogastroenterology 50(suppl 2):ccxix-ccxxi

31. Hussein Z, Beerahee M, Grover R, Jordan B, Jeffs R, Donaldson J, Zaccardelli D, Colice G, Guntupalli K, Watson D, Vincent JL 1999 Pharmacokinetics of the nitric oxide synthase inhibitor L-NG-methylarginine hydrochloride in patients with septic shock. Glaxo Wellcome International Septic Shock Study Group. Clin Pharmacol Ther 65:1-9

32. Mayer BX, Mensik C, Krishnaswami S, Derendorf H, Eichler HG, Schmetterer L, Woltz M 1999 Pharmacokinetic-pharmacodynamic profile of systemic nitric oxidesynthase inhibition with L-NMMA in humans. Br J Clin Pharmacol 47:539-544 